\title{
PENGARUH LINGKUNGAN KERJA DAN DISIPLIN KERJA TERHADAP PRODUKTIVITAS KARYAWAN PADA PT. GRAHA CURAH NIAGA DI TANGERANG
}

\section{THE INFLUENCE OF WORK ENVIRONMENT AND WORK DISCIPLINE ON EMPLOYEE PRODUCTIVITY AT PT. GRAHA CURAH NIAGA IN TANGERANG}

\author{
${ }^{1}$ Kosasih, ${ }^{2}$ Nurjaya, ${ }^{3}$ Heri Sapari Kahpi, ${ }^{4}$ Azhar Affandi, ${ }^{5 *}$ Denok Sunarsi \\ ${ }^{1 *}$ Universitas Sangga Buana, Bandung, Jawa Barat, Indonesia \\ ${ }^{2}$ Universitas Suryakancana, Cianjur, Jawa Barat, Indonesia \\ ${ }^{3}$ STIE Banten, Kota Serang, Banten, Indonesia \\ ${ }^{4}$ Universitas Pasundan, Bandung, Jawa Barat, Indonesia \\ ${ }^{5}$ Universitas Pamulang, Tangerang Selatan, Jawa Barat, Indonesia
}

\section{*denoksunarsi@unpam.ac.id}

\begin{tabular}{|l|l|l}
\hline Masuk: 23 Mei 2021 & Penerimaan: 24 Mei 2021 & Publikasi: 28 Juni 2021 \\
\hline
\end{tabular}

\begin{abstract}
ABSTRAK
Penelitian ini bertujuan untuk mengetahui pengaruh lingkungan kerja dan disiplin kerja terhadap produktivitas karyawan pada PT. Graha Curah Niaga di Tangerang. Metode yang digunakan adalah explanatory research dengan teknik analisis menggunakan analisis statistik dengan pengujian regresi, korelasi, determinasi dan uji hipotesis. Hasil penelitian ini Lingkungan Kerja berpengaruh signifikan terhadap produktivitas karyawan sebesar 43,6\%, uji hipotesis diperoleh $\mathrm{t}$ hitung $>\mathrm{t}$ tabel atau $(11,425$ $>1,974)$. Disiplin Kerja berpengaruh signifikan terhadap produktivitas karyawan sebesar 41,1\%, uji hipotesis diperoleh $\mathrm{t}$ hitung $>\mathrm{t}$ tabel atau $(10,852>1,974)$. Lingkungan Kerja dan Disiplin Kerja secara simultan berpengaruh signifikan terhadap produktivitas karyawan dengan persamaan regresi $\mathrm{Y}$ $=10,259+0,387 \mathrm{X} 1+0,355 \mathrm{X} 2$ dan kontribusi pengaruh sebesar 52,0\%, uji hipotesis diperoleh $\mathrm{F}$ hitung $>\mathrm{F}$ tabel atau $(18,770>2,660)$.
\end{abstract}

Kata Kunci: Lingkungan Kerja, Disiplin Kerja, Produktivitas Karyawan.

\begin{abstract}
This research aims to determine the influence of work environment and work discipline on employee productivity in PT. Graba Curah Niaga in Tangerang. The method used is explanatory research with analytical techniques using statistical analysis with regression testing, correlation, determination and hypothesis testing. The results of this study work environment significantly affect employee productivity by 43.6\%, hypothetical test obtained $t$ calculate $>t$ table or $(11,425>1,974)$. Work. Discipline significantly affected employee productivity by $41.1 \%$, bypothesis test obtained $t$ count $>t$ table or $(10,852>1,974)$. Work. Environment and Work. Discipline simultaneously significantly affect employee productivity with regression equation $Y=10,259+0.387 \mathrm{X} 1+0.355 \mathrm{X} 2$ and influence contribution of $52.0 \%$, bypothesis test obtained $F$ calculate $>$ F table or $(18,770>2,660)$.
\end{abstract}

Keywords: Work Environment, Work Discipline, Employee Productivity.

\section{PENDAHULUAN}


Pengaruh Lingkungan Kerja dan Disiplin Kerja terhadap Produktivitas Karyawan pada PT. Graha Curah Niaga di Tangerang

Kosasih, Nurjaya, Heri Sapari Kahpi, Azhar Affandi, Denok Sunarsi

\section{Latar Belakang Masalah}

Manajemen sumber daya manusia merupakan bagian dari manajemen keorganisasian yang memfokuskan diri pada unsur sumber daya manusia. Sumber daya manusia dalam suatu organisasi mempunyai peranan yang sangat penting, karena segala upaya yang dilakukan dalam meraih tujuan organisasi harus dengan efektifitas penggunaan sumber daya yang efisien. Seiring dengan meningkatnya ukuran dan aktivitas organisasi juga akan semakin meningkatkan kegiatan pihak manajemen. Organisasi yang besar dan kompleks, menuntut organisasi memiliki pusat pertanggungjawaban yang akan melaksanakan kegiatan, mengawasi, dan mengevaluasi produktivitasnya agar dapat dicapai sehingga dapat meningkatkan hasil yang maksimal sesuai dengan tujuan umum organisasi. Tugas manajemen sumber daya manusia adalah mengelola unsur manusia secara baik agar diperoleh tenaga kerja yang puas akan pekerjaannya di dalam organisasi. Manusia merupakan salah satu unsur yang terpenting di dalam suatu organisasi, tanpa peran manusia meskipun berbagai faktor yang dibutuhkan itu telah tersedia, organisasi tidak akan berjalan tanpa adanya pengelolaan yang tepat dalam organisasi.

Ketatnya persaingan dunia industri saat ini merupakan fenomena yang tidak dapat dihindarkan dalam dunia industri sekaligus menghadirkan berbagai ancaman serta peluang bagi setiap lembaga bisnis. Oleh karena itu, untuk memanfaatkan peluang yang ada, maka organisasi atau perusahaan dituntut untuk memahami dan merespon keinginan serta kebutuhan konsumen dari pasar yang menjadi sasaran perusahaan. untuk memenangkan persaingan di pasar setiap perusahaan harus menjaga dan meningkatkan kualitas produktivitas perusahaan. Salah satu peran penting yang harus ditekankan oleh suatu perusahaan agar dapat mencapai tujuannya adalah dengan menciptakan lingkungan kerja yang baik bagi para karyawannya secara fisik maupun lingkungan kerja non fisik Seperti persepsi dan para karyawan mengenai lingkungan kerja yang mereka dapatkan sehingga karyawan dapat memberikan penilaian yang berbeda atas segala aspek dari lingkungan kerja. Apabila persepsi yang ditunjukkan karyawan itu baik maka akan mempengaruhi produktivitas karyawan itu baik pula karena dapat membuat para karyawan merasa lebih nyaman dan menyenangkan dengan keadaan lingkungan kerja yang baik, sedangkan apabila persepsi yang ditunjukkan karyawan buruk maka produktivitas dari karyawan tersebut juga akan berkurang.

Menurut Sedarmayanti (2017) "lingkungan kerja adalah keseluruhan alat perkakas dan bahan yang dihadapi, lingkungan sekitarnya dimana seseorang bekerja, metode kerjanya, serta pengaturan kerjanya baik sebagai perseorangan maupun sebagai kelompok". Produktivitas akan tinggi dan otomatis prestasi kerja karyawan juga tinggi lingkungan kerja itu mencakup hubungan kerja antara bawahan dan atasan serta lingkungan fisik tempat karyawan bekerja.

Lingkungan kerja mempunyai kontribusi yang cukup besar dalam peningkatan kerja. Lingkungan kerja mengarah kepada beberapa aspek diantaranya manajemen, struktur organisasi, dan deskripsi kerja. Lingkungan fisik yang memuaskan, seperti tempat ibadah, ruangan yang cukup nyaman untuk bekerja, keamanan, dan jam kerja yang sesuai. Selain itu rancangan ruang kerja yang memperhatikan jumlah ruang kerja, tata letak, dan tingkat kekuasaan pribadi yang diberikan, mempengaruhi produktifitas dan tingkat kepuasan karyawan.

Dalam memperoleh data lingkungan kerja peneliti melakukan pra survei dengan cara menyebarkan kuesioner kepada 48 karyawan PT. Graha Curah Niaga terkait dengan kondisi lingkungan kerja. Berikut ini adalah data pra survei terkait lingkungan kerja pada perusahaan tersebut, ditunjukan pada table berikut ini: 
Pengaruh Lingkungan Kerja dan Disiplin Kerja terhadap Produktivitas Karyawan pada PT. Graha Curah Niaga di Tangerang

Kosasih, Nurjaya, Heri Sapari Kahpi, Azhar Affandi, Denok Sunarsi

Tabel 1. Kuesioner Pra Penelitian Tentang Lingkungan Kerja yang Terjadi di PT. Graha Curah Niaga Periode 2017-2019

\begin{tabular}{|c|c|c|c|c|}
\hline \multirow{2}{*}{ Aspek Penelitian } & \multicolumn{3}{|c|}{ Keterangan } & \multirow{2}{*}{ Jumlah } \\
\cline { 2 - 4 } & SB & B & TB & \\
\hline Penerangan Cahaya & 12 & 15 & 21 & 48 \\
\hline Suhu Udara & 15 & 13 & 20 & 48 \\
\hline Suara Bising & 17 & 15 & 16 & 48 \\
\hline Penggunaan Warna & 19 & 12 & 17 & 48 \\
\hline Keamanan & 11 & 13 & 24 & 48 \\
\hline Jumlah & 74 & 68 & 98 & 240 \\
\hline Presentase & $30.8 \%$ & $28.3 \%$ & $40.8 \%$ & $100 \%$ \\
\hline
\end{tabular}

Sumber: Data Pra Survei Awal Data Lingkungan Kerja PT. Graha Curah Niaga

Berdasarkan data diatas, pada PT. Graha Curah Niaga bahwa lingkungan kerja 40,8\% menjawab tidak baik, dengan jumlah respon 24 menjawab tidak baik terhadap keamanan, berarti lingkungan kerja yang ada pada PT. Graha Curah Niaga belum terjaga dengan baik keamanannya dan diharapkan oleh karyawan tersebut.

Selain lingkungan kerja yang dapat mempengaruhi guna peningkatan produktivitas. Ada juga faktor lain yaitu disiplin kerja yang dapat mempengaruhi peningkatan produktivitas kerja. Kegiatan pendisiplinan yang dilaksanakan akan mendorong para karyawan agar mengikuti berbagai standard dan aturan, sehingga penyelewengan-penyelewengan dapat dicegah. Sasaran pokoknya adalah untuk mendorong disiplin diri diantara para karyawan untuk datang di kantor tepat waktu. Dengan datang tepat waktu, maka diharapkan mampu menjalankan tugasnya dan dapat meningkatkan produktivitas kerja. Dengan adanya produktivitas kerja maka perlu adanya disiplin kerja sehingga dapat mencapai target sesuai dengan target suatu instansi. Menurut Hasibuan (2016), “disiplin kerja adalah kesadaran dan kesediaan seseorang menaati semua peraturan dan norma-norma sosial yang berlaku. Kesadaran adalah sikap seseorang yang secara sukarela menaati semua peraturan dan sadar akan tugas dan tanggung jawabnya, kesediaan adalah suatu sikap dan tingkah laku dalam melaksanakan peraturan perusahaan, baik yang tertulis maupun tidak".

Observasi yang telah dilakukan masih banyak yang terlambat saat masuk jam kerja, dan kurangnya lingkungan kerja yang baik, karena produktivitas kerja karyawan sendiri dipengaruhi oleh karakteristik individu dan faktor lingkungan perusahaan, baik suasana kerja lingkungan fisik maupun leadership dari pimpinan. Menurut Sutrisno (2016) "produktivitas kerja adalah rasio dari hasil kerja dengan waktu yang dibutuhkan untuk menghasilkan produk dari seorang tenaga kerja". Berikut ini tabel tentang perbandingan tanggung jawab karyawan terhadap pekerjaan yang diberkan pada karyawan.

Data diatas menunjukkan bahwa produktivitas kerja karyawan selama periode dari tahun 2017 - 2019 dapat disimpulkan hanya 18 karyawan yang produktivitasnya sangat baik di tahun 2019, dibandingkan pada tahun 2018 yaitu sebanyak 20 karyawan, dan pada tahun 2017 yaitu sebanyak 25 karyawan. Penilaian produktivitas kerja dengan kategori cukup baik pada tahun 2019 yaitu sebanyak 15 karyawan sebelumnya sebanyak 15 karyawan pada tahun 2018, dan 13 karyawan pada tahun 2017. Dan untuk penilaian produktivitas kategori kurang baik pada tahun 2019 yaitu sebanyak 15 karyawan sementara pada tahun 2018 hanya 13 karyawan dan 10 karyawan pada tahun 2017. Sehingga dapat dilihat bahwa produktivitas karyawan pada PT. Graha Curah Niaga cabang Tangerang 1 mengalami 
Pengaruh Lingkungan Kerja dan Disiplin Kerja terhadap Produktivitas Karyawan pada PT. Graha Curah Niaga di Tangerang

Kosasih, Nurjaya, Heri Sapari Kahpi, Azhar Affandi, Denok Sunarsi

penurunan. Berdasarkan latar belakang permasalahan diatas, maka penulis tertarik untuk melakukan penelitian lebih lanjut dengan judul "Pengaruh Lingkungan Kerja dan Disiplin Kerja Terhadap Produktivitas Karyawan Pada PT. Graha Curah Niaga di Tangerang.

\section{Rumusan Masalah}

a. Adakah pengaruh antara Lingkungan Kerja terhadap produktivitas karyawan pada PT. Graha Curah Niaga di Tangerang?

b. Adakah pengaruh antara Disiplin Kerja terhadap produktivitas karyawan pada PT. Graha Curah Niaga di Tangerang?

c. Adakah pengaruh secara simultan antara Lingkungan Kerja dan Disiplin Kerja terhadap produktivitas karyawan pada PT. Graha Curah Niaga di Tangerang ?

\section{Tujuan Penelitian}

a. Untuk mengetahui pengaruh antara Lingkungan Kerja terhadap produktivitas karyawan pada PT. Graha Curah Niaga di Tangerang.

b. Untuk mengetahui pengaruh antara Disiplin Kerja terhadap produktivitas karyawan pada PT. Graha Curah Niaga di Tangerang.

c. Untuk mengetahui pengaruh secara simultan antara Lingkungan Kerja dan Disiplin Kerja terhadap produktivitas karyawan pada PT. Graha Curah Niaga di Tangerang.

\section{METODE PENELITIAN}

1. Populasi

Populasi dalam penelitian ini berjumlah 171 responden PT. Graha Curah Niaga di Tangerang

\section{Sampel}

Sampel dalam penelitian ini berjumlah 171 responden.

\section{Jenis Penelitian}

Jenis penelitian yang dipakai adalah asosiatif, dimana tujuannya adalah untuk mengetahui pengaruh antara variabel bebas terhadap variabel terikat baik parsial maupun simultan

\section{Metode Analisis Data}

Dalam menganalisis data digunakan uji instrumen, uji asumsi klasik, regresi, koefisien determinasi dan uji hipotesis.

\section{HASIL DAN PEMBAHASAN}

\section{Analisis Deskriptif}

Pada pengujian ini digunakan untuk mengetahui skor minimum dan maksimum, mean score dan standar deviasi dari masing-masing variabel. Adapun hasilnya sebagai berikut:

Tabel 2. Hasil Analisis Descriptive Statistics

\section{Descriptive Statistics}

\begin{tabular}{ll|r|r|r|r} 
& N & \multicolumn{1}{|c|}{ Minimum } & Maximum & Mean & \multicolumn{1}{c}{ Std. Deviation } \\
\hline Lingkungan Kerja (X1) & 171 & 29 & 48 & 37.86 & 3.875 \\
\hline Disiplin Kerja (X2) & 171 & 29 & 46 & 37.54 & 3.706 \\
\hline Produktivitas Karyawan (Y) & 171 & 28 & 46 & 38.25 & 3.523 \\
\hline Valid N (listwise) & 171 & & & & \\
\hline
\end{tabular}

Lingkungan Kerja diperoleh varians minimum sebesar 29 dan varians maximum 48 dengan mean score sebesar 37,86dengan standar deviasi 3,875.

Disiplin Kerja diperoleh varians minimum sebesar 29 dan varians maximum 46 dengan mean score sebesar 37,54 dengan standar deviasi 3,705. 
Pengaruh Lingkungan Kerja dan Disiplin Kerja terhadap Produktivitas Karyawan pada PT. Graha Curah Niaga di Tangerang

Kosasih, Nurjaya, Heri Sapari Kahpi, Azhar Affandi, Denok Sunarsi

Produktivitas karyawan diperoleh varians minimum sebesar 28 dan varians maximum 47 dengan mean score sebesar 38,25 dengan standar deviasi 3,523.

\section{Analisis Verifikatif.}

Pada analisis ini dimaksudkan untuk mengetahui pengaruh variabel independen terhadap variabel dependen. Adapun hasil pengujian sebagai berikut:

\section{a. Analisis Regresi Linier Berganda}

Uji regresi ini dimaksudkan untuk mengetahui perubahan variabel dependen jika variabel independen mengalami perubahan. Adapun hasil pengujiannya sebagai berikut:

Tabel 3. Hasil Pengujian Regresi Linier Berganda

\section{Coefficients $^{\mathrm{a}}$}

\begin{tabular}{|c|c|c|c|c|c|}
\hline \multirow[b]{2}{*}{ Model } & \multicolumn{2}{|c|}{$\begin{array}{c}\text { Unstandardized } \\
\text { Coefficients }\end{array}$} & \multirow{2}{*}{$\begin{array}{c}\text { Standardized } \\
\text { Coefficients } \\
\text { Beta } \\
\end{array}$} & \multirow[b]{2}{*}{$\mathrm{t}$} & \multirow[b]{2}{*}{ Sig. } \\
\hline & $\mathrm{B}$ & Std. Error & & & \\
\hline 1 (Constant) & 10.259 & 2.086 & & 4.918 & .000 \\
\hline Lingkungan Kerja (X1) & .387 & .062 & .426 & 6.201 & .000 \\
\hline Disiplin Kerja (X2) & .355 & .065 & .374 & 5.446 & .000 \\
\hline
\end{tabular}

a. Dependent Variable: Produktivitas Karyawan (Y)

Berdasarkan hasil pengujian pada tabel di atas, diperoleh persamaan regresi $\mathrm{Y}=10,259+$ 0,387X1 + 0,355X2. Dari persamaan tersebut dijelaskan sebagai berikut:

1) Konstanta sebesar 10,259 diartikan jika Lingkungan Kerja dan Disiplin Kerja tidak ada, maka telah terdapat nilai produktivitas karyawan sebesar 10,259 point.

2) Koefisien regresi Lingkungan Kerja sebesar 0,387, angka ini positif artinya setiap ada peningkatan Lingkungan Kerja sebesar 0,387 maka produktivitas karyawan juga akan mengalami peningkatan sebesar 0,387 point.

3) Koefisien regresi Disiplin Kerja sebesar 0,355, angka ini positif artinya setiap ada peningkatan Disiplin Kerja sebesar 0,355 maka produktivitas karyawan juga akan mengalami peningkatan sebesar 0,355 point.

\section{b. Analisis Koefisien Korelasi}

Analisis koefisien korelasi dimaksudkan untuk mengetahui tingkt kekuatan hubungan dari variabel independen terhadap variabel dependen baik secara parsial maupun simultan. Adapun hasil pengujian sebagai berikut:

Tabel 4. Hasil Pengujian Koefisien Korelasi Lingkungan Kerja Terhadap Produktivitas Karyawan.

\begin{tabular}{llr|r} 
& \multicolumn{1}{c}{ Correlations $^{\mathbf{b}}$} & $\begin{array}{r}\text { Lingkungan Kerja } \\
\text { (X1) }\end{array}$ & $\begin{array}{r}\text { Produktivitas } \\
\text { Karyawan (Y) }\end{array}$ \\
\hline Lingkungan Kerja (X1) & Pearson Correlation & 1 & $.660^{* *}$ \\
\cline { 2 - 4 } & Sig. (2-tailed) & .000 \\
\hline Produktivitas Karyawan (Y) & Pearson Correlation & $.660^{* *}$ & 1 \\
\cline { 2 - 4 } & Sig. (2-tailed) & .000 & \\
\hline
\end{tabular}

**. Correlation is significant at the 0.01 level (2-tailed).

b. Listwise $\mathrm{N}=171$

Berdasarkan hasil pengujian diperoleh nilai korelasi sebesar 0,660 artinya Lingkungan Kerja memiliki hubungan yang kuat terhadap produktivitas karyawan. 
Pengaruh Lingkungan Kerja dan Disiplin Kerja terhadap Produktivitas Karyawan pada PT. Graha Curah Niaga di Tangerang

Kosasih, Nurjaya, Heri Sapari Kahpi, Azhar Affandi, Denok Sunarsi

Tabel 5. Hasil Pengujian Koefisien Korelasi Disiplin Kerja Terhadap Produktivitas Karyawan.

\section{Correlations $^{\mathrm{b}}$}

\begin{tabular}{|c|c|c|c|}
\hline & & Disiplin Kerja (X2) & $\begin{array}{l}\text { Produktivitas } \\
\text { Karyawan (Y) }\end{array}$ \\
\hline \multirow[t]{2}{*}{ Disiplin Kerja (X2) } & Pearson Correlation & 1 & $.641^{* *}$ \\
\hline & Sig. (2-tailed) & & .000 \\
\hline \multirow[t]{2}{*}{ Produktivitas Karyawan (Y) } & Pearson Correlation & $.641^{* *}$ & 1 \\
\hline & Sig. (2-tailed) & .000 & \\
\hline
\end{tabular}

Berdasarkan hasil pengujian diperoleh nilai korelasi sebesar 0,641 artinya Disiplin Kerja memiliki hubungan yang kuat terhadap produktivitas karyawan.

Tabel 6. Hasil Pengujian Koefisien Korelasi Lingkungan Kerja dan Disiplin Kerja secara simultan Terhadap Produktivitas Karyawan.

\section{Model Summary}

\begin{tabular}{|c|c|c|c|c|}
\hline Model & $\mathrm{R}$ & R Square & $\begin{array}{l}\text { Adjusted R } \\
\text { Square }\end{array}$ & Std. Error of the Estimate \\
\hline 1 & $.721^{\mathrm{a}}$ & .520 & .515 & 2.454 \\
\hline
\end{tabular}

Berdasarkan hasil pengujian diperoleh nilai korelasi sebesar 0,721 artinya Lingkungan Kerja dan Disiplin Kerja secara simultan memiliki hubungan yang kuat terhadap produktivitas karyawan.

\section{c. Analisis Koefisien Determinasi}

Analisis koefisien determinasi dimaksudkan untuk mengetahui besarnya persentase pengaruh dari variabel independen terhadap variabel dependen baik secara parsial maupun simultan. Adapun hasil pengujian sebagai berikut:

Tabel 7. Hasil Pengujian Koefisien Determinasi Lingkungan Kerja Terhadap Produktivitas

$$
\text { Karyawan. }
$$

\section{Model Summary}

\begin{tabular}{|c|c|c|c|c|}
\hline Model & $\mathrm{R}$ & R Square & $\begin{array}{l}\text { Adjusted R } \\
\text { Square }\end{array}$ & $\begin{array}{l}\text { Std. Error of the } \\
\text { Estimate }\end{array}$ \\
\hline$\overline{1}$ & $.660^{a}$ & .436 & .432 & 2.654 \\
\hline
\end{tabular}


Pengaruh Lingkungan Kerja dan Disiplin Kerja terhadap Produktivitas Karyawan pada PT. Graha Curah Niaga di Tangerang

Kosasih, Nurjaya, Heri Sapari Kahpi, Azhar Affandi, Denok Sunarsi

Tabel 8. Hasil Pengujian Koefisien Determinasi Disiplin Kerja Terhadap Produktivitas Karyawan.

\section{Model Summary}

\begin{tabular}{|c|c|c|c|c|}
\hline Model & $\mathrm{R}$ & R Square & $\begin{array}{l}\text { Adjusted R } \\
\text { Square }\end{array}$ & $\begin{array}{l}\text { Std. Error of the } \\
\text { Estimate }\end{array}$ \\
\hline$\overline{1}$ & $.641^{a}$ & .411 & .407 & 2.712 \\
\hline
\end{tabular}

Berdasarkan hasil pengujian diperoleh nilai determinasi sebesar 0,411 artinya Disiplin Kerja memiliki kontribusi pengaruh sebesar 41,1\% terhadap produktivitas karyawan.

Tabel 9. Hasil Pengujian Koefisien Determinasi Lingkungan Kerja dan Disiplin Kerja Terhadap Produktivitas Karyawan.

\section{Model Summary}

\begin{tabular}{|c|c|c|c|c|}
\hline Model & $\mathrm{R}$ & R Square & $\begin{array}{l}\text { Adjusted R } \\
\text { Square }\end{array}$ & $\begin{array}{l}\text { Std. Error of the } \\
\text { Estimate }\end{array}$ \\
\hline 1 & $.721^{a}$ & .520 & .515 & 2.454 \\
\hline
\end{tabular}

Berdasarkan hasil pengujian diperoleh nilai determinasi sebesar 0,520 artinya Lingkungan Kerja dan Disiplin Kerja secara simultan memiliki kontribusi pengaruh sebesar 52,0\% terhadap produktivitas karyawan, sedangkan sisanya sebesar 48,0\% dipengaruhi faktor lain.

\section{d. Uji Hipotesis}

\section{Uji hipotesis Parsial (Uji t)}

Pengujian hipotesis dengan uji $\mathrm{t}$ digunakan untuk mengetahui hipotesis parsial mana yang diterima.

Hipotesis pertama: Terdapat pengaruh yang signifikan antara Lingkungan Kerja terhadap produktivitas karyawan.

Tabel 10. Hasil Uji Hipotesis Lingkungan Kerja Terhadap Produktivitas Karyawan.

\section{Coefficients $^{\mathrm{a}}$}

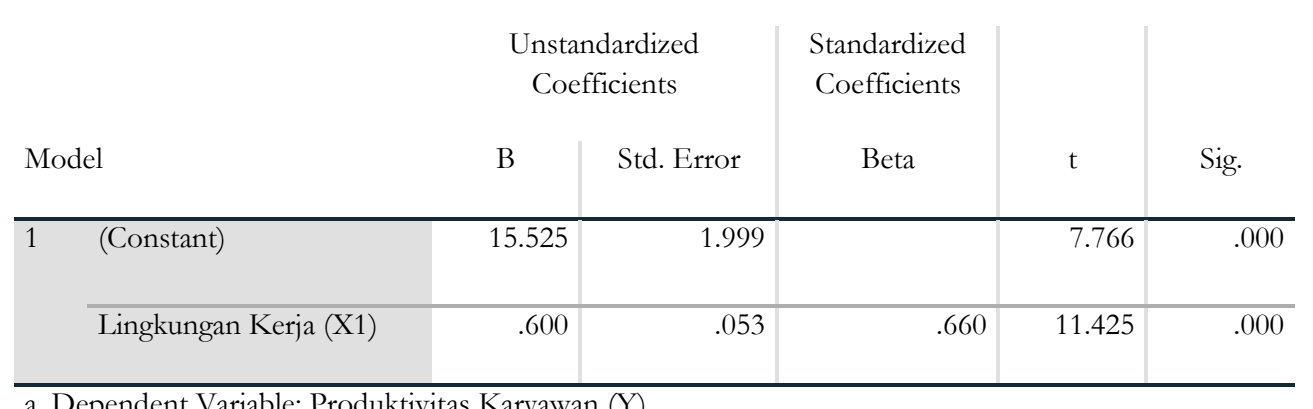

a. Dependent Variable: Produktivitas Karyawan (Y) 
Pengaruh Lingkungan Kerja dan Disiplin Kerja terhadap Produktivitas Karyawan pada PT. Graha Curah Niaga di Tangerang

Kosasih, Nurjaya, Heri Sapari Kahpi, Azhar Affandi, Denok Sunarsi

Berdasarkan hasil pengujian pada tabel di atas, diperoleh nilai $\mathrm{t}$ hitung $>\mathrm{t}$ tabel atau $(11,425>1,974)$, dengan demikian hipotesis pertama yang diajukan bahwa terdapat pengaruh yang signifikan atara Lingkungan Kerja terhadap produktivitas karyawan diterima.

Tabel 11. Hasil Uji Hipotesis Disiplin Kerja Terhadap Produktivitas Karyawan.

\section{Coefficients $^{\mathrm{a}}$}

\begin{tabular}{|c|c|c|c|c|c|}
\hline \multirow[b]{2}{*}{ Model } & \multicolumn{2}{|c|}{$\begin{array}{c}\text { Unstandardized } \\
\text { Coefficients }\end{array}$} & \multirow{2}{*}{$\begin{array}{c}\text { Standardized } \\
\text { Coefficients } \\
\text { Beta }\end{array}$} & \multirow[b]{2}{*}{$\mathrm{t}$} & \multirow[b]{2}{*}{ Sig. } \\
\hline & B & Std. Error & & & \\
\hline $\begin{array}{ll}1 & \text { (Constant) }\end{array}$ & 15.373 & 2.118 & & 7.259 & .000 \\
\hline Disiplin Kerja (X2) & .609 & .056 & .641 & 10.852 & .000 \\
\hline
\end{tabular}

a. Dependent Variable: Produktivitas Karyawan (Y)

Berdasarkan hasil pengujian pada tabel di atas, diperoleh nilai $\mathrm{t}$ hitung $>\mathrm{t}$ tabel atau $(10,852>1,974)$, dengan demikian hipotesis kedua yang diajukan bahwa terdapat pengaruh yang signifikan atara Disiplin Kerja terhadap produktivitas karyawan diterima.

\section{Uji Hipotesis Simultan (Uji F)}

Pengujian hipotesis dengan uji $\mathrm{F}$ digunakan untuk mengetahui hipotesis simultan yang mana yang diterima.

Hipotesis ketiga Terdapat pengaruh yang signifikan antara Lingkungan Kerja dan Disiplin Kerja terhadap produktivitas karyawan.

Tabel 12. Hasil Uji Hipotesis Lingkungan Kerja dan Disiplin Kerja Terhadap Produktivitas Karyawan.

\begin{tabular}{|c|c|c|c|c|c|c|}
\hline \multicolumn{7}{|c|}{ ANOVA $^{a}$} \\
\hline Model & & Sum of Squares & df & Mean Square & F & Sig. \\
\hline \multirow[t]{3}{*}{1} & Regression & 1097.956 & 2 & 548.978 & 91.159 & $.000^{\mathrm{b}}$ \\
\hline & Residual & 1011.728 & 168 & 6.022 & & \\
\hline & Total & 2109.684 & 170 & & & \\
\hline
\end{tabular}

a. Dependent Variable: Produktivitas Karyawan (Y)

b. Predictors: (Constant), Disiplin Kerja (X2), Lingkungan Kerja (X1)

Berdasarkan hasil pengujian pada tabel di atas, diperoleh nilai $\mathrm{F}$ hitung $>\mathrm{F}$ tabel atau $(18,770>$ 2,660), dengan demikian hipotesis ketiga yang diajukan bahwa terdapat pengaruh yang signifikan atara Lingkungan Kerja dan Disiplin Kerja terhadap produktivitas karyawan diterima.

\section{PEMBAHASAN HASIL PENELITIAN}

\section{Pengaruh Lingkungan Kerja Terhadap Produktivitas Karyawan}

Lingkungan Kerja berpengaruh signifikan terhadap produktivitas karyawan dengan korelasi sebesar 0,660 atau memiliki hubungan yang kuat dengan kontribusi pengaruh sebesar 43,6\%. Pengujian hipotesis diperoleh nilai $\mathrm{t}$ hitung $>\mathrm{t}$ tabel atau $(11,425>1,974)$. Dengan demikian 
Pengaruh Lingkungan Kerja dan Disiplin Kerja terhadap Produktivitas Karyawan pada PT. Graha Curah Niaga di

Tangerang

Kosasih, Nurjaya, Heri Sapari Kahpi, Azhar Affandi, Denok Sunarsi

hipotesis pertama yang diajukan bahwa terdapat berpengaruh signifikan antara Lingkungan Kerja terhadap produktivitas karyawan diterima.

\section{Pengaruh Disiplin Kerja Terhadap Produktivitas Karyawan}

Disiplin Kerja berpengaruh signifikan terhadap produktivitas karyawan dengan korelasi sebesar 0,641 atau memiliki hubungan yang kuat dengan kontribusi pengaruh sebesar $41,1 \%$. Pengujian hipotesis diperoleh nilai t hitung $>\mathrm{t}$ tabel atau $(10,852>1,974)$. Dengan demikian hipotesis kedua yang diajukan bahwa terdapat berpengaruh signifikan antara Disiplin Kerja terhadap produktivitas karyawan diterima.

\section{Pengaruh Lingkungan Kerja dan Disiplin Kerja Terhadap Produktivitas Karyawan}

Lingkungan Kerja dan Disiplin Kerja berpengaruh signifikan terhadap produktivitas karyawan dengan diperoleh persamaan regresi $\mathrm{Y}=10,259+0,387 \mathrm{X} 1+0,355 \mathrm{X} 2$, nilai korelasi sebesar 0,721 atau memiliki hubungan yang kuat dengan kontribusi pengaruh sebesar 52,0\% sedangkan sisanya sebesar 48,0\% dipengaruhi faktor lain. Pengujian hipotesis diperoleh nilai $\mathrm{F}$ hitung $>\mathrm{F}$ tabel atau $(18,770>2,660)$. Dengan demikian hipotesis ketiga yang diajukan bahwa terdapat berpengaruh signifikan antara Lingkungan Kerja dan Disiplin Kerja terhadap produktivitas karyawan diterima.

\section{KESIMPULAN DAN SARAN}

\section{Kesimpulan}

a. Lingkungan Kerja berpengaruh signifikan terhadap produktivitas karyawan dengan kontribusi pengaruh sebesar 43,6\%. Uji hipotesis diperoleh nilai t hitung $>\mathrm{t}$ tabel atau $(11,425>1,974)$.

b. Disiplin Kerja berpengaruh signifikan terhadap produktivitas karyawan dengan kontribusi pengaruh sebesar 41,1\%. Uji hipotesis diperoleh nilai $t$ hitung $>t$ tabel atau $(10,852>1,974)$.

c. Lingkungan Kerja dan Disiplin Kerja berpengaruh signifikan terhadap produktivitas karyawan dengan kontribusi pengaruh sebesar 52,0\% sedangkan sisanya sebesar 48,0\% dipengaruhi faktor lain. Uji hipotesis diperoleh nilai $\mathrm{F}$ hitung $>\mathrm{F}$ tabel atau $(18,770>2,660)$.

\section{Saran}

a. Perusahaan harus melengkapi fasilitas peralatan kerja dan kondisi pabrik yang kurang bersih serta agar karyawan merasa betah bekerja

b. Perusahaan harus selalu memberikan semangat dan apresiasi yang layak untuk memastikan karyawan memiliki semangat kerja yang tinggi.

c. Produktivitas perusahaan dapat ditingkatkan dengan memberdayakan karyawan dengan menegakkan peraturan yang baik dan pemberian Disiplin Kerja yang lebih inten lagi.

\section{DAFTAR PUSTAKA}

Algifari. (2015). “Analisis Regresi untuk Bisnis dan Ekonomi”. Yogyakarta: BPFE.

Arikunto, Suharsimi (2014). "Prosedur Penelitian Suatu Pendekatan Praktek”. Jakarta: Rineka Cipta.

Edi Sutrisno (2016). Manajemen Sumber Daya Manusia. Jakarta: Prenadamedia Group.

Fandy Tjiptono (2017), Serivce Quality and Satisfiation. Jakarta: Edisi tiga. Andi.

Freddy Rangkuti (2016) Strategi Promosi Yang Kreatif, Edisi Pertama, Cetakan Pertama Jakarta: Gramedia Pustaka Utama 
Pengaruh Lingkungan Kerja dan Disiplin Kerja terhadap Produktivitas Karyawan pada PT. Graha Curah Niaga di Tangerang

Kosasih, Nurjaya, Heri Sapari Kahpi, Azhar Affandi, Denok Sunarsi

Freed Luthans (2016) Organizational Behavior, McGraw-Hill, New York.

Handoko (2016) Manajemen Personalia dan Sumberdaya Manusia. Yogyakarta: BPFE.

Hasibuan (2016) "Manajemen Sumber Daya Manusia”. Haji Masagung. Jakarta.

Henry Simamora (2005), Manajemen Sumber Daya Manusia, STIE YKPN Bandung.

Heri Sapari Kahpi, et al (2019). Pengaruh Pengembangan Karir Dan Pelatihan Kerja Terhadap Kinerja Pegawai Pada Dinas Perhubungan Kota Serang. Jurnal Ekonomi Efektif. Vol 1, No 4

Imam Ghozali (2017). “Aplikasi Analisis Multivariate Dengan Program SPSS”. Edisi Kelima. Semarang: Badan Penerbit Undip.

Istijanto (2014) “Riset Sumber Daya Manusia”. Jakarta: PT. Gramedia Pustaka

Komarudin, K. (2018). Pengaruh Lingkungan Kerja Terhadap Kinerja Karyawan Pada PT. Pos Indonesia Depok. JENIUS (Jumal Ilmiah Manajemen Sumber Daya Manusia), 1(3).

Kristianti, L. S., Affandi, A., Nurjaya, N., Sunarsi, D., \& Rozi, A. (2021). Pengaruh Motivasi Dan Disiplin Kerja Terhadap Kinerja Pegawai Pada Dinas Pariwisata Purwakarta. Jurnal Ilmah PERKUSI, 1(1), 101-109.

Mangkunegara, Prabu Anwar. (2016). Evaluasi Produktivitas SDM. Cetakan ke tujuh, PT Refika Aditama: Bandung.

Nitisemito, Alek.S, (2010), Manajemen Personalia, Ghalia Indonesia, Jakarta.

Nurjaya, N., Sobarna, A., Affandi, A., Erlangga, H., \& Sarwani, S. (2020). Edupreneurship management in shaping the nation's character. Jurnal Konseling dan Pendidikan, 8(3), 198-206.

Nurjaya, N., Sunarsi, D., Effendy, A. A., Teriyan, A., \& Gunartin, G. (2021). Pengaruh Etos Kerja Dan Disiplin Kerja Terhadap Kinerja Pegawai Pada Dinas Kehutanan Dan Perkebunan Kota Bogor. JENIUS (Jurnal Ilmiah Manajemen Sumber Daya Manusia), 4(2), 172-184.

Rivai Veithzal (2015) Manajemen Sumber Daya Manusia Untuk Perusabaan. Penerbit $\quad$ PT Raja Grafindo Persada, Jakarta, 2010.

Santoso, Singgih (2015). “Menguasai Statistik Multivariat”. Jakarta: PT Elex Media Komputindo.

Sedarmayanti (2016) Manajemen Sumber Daya Manusia, Reformasi Birokrasi dan Manajemen Karyawan Negeri Sipil, Cetakan Kelima, Bandung: PT Refika Aditama.

Siagian, S (2007). Manajemen Sumber Daya Manusia. Jakarta: Bumi Aksara.

Sinamo, J. (2011). Delapan Etos Kerja Profesional. Jakarta: Institut

Sugiyono (2017), “Metode Penelitian Administrasi : dilengkapi dengan Metode R \& D”. Bandung: Alfabeta. 